\title{
SINCRETISMO AFRO-BRASILEIRO, POLITEÍSMO \\ E QUESTÕES AFINS
}

\author{
Reginaldo Prandi ${ }^{I}$
}

\begin{abstract}
Resumo: $O$ presente artigo trata do sincretismo religioso na formação e posteriores transformações das religiōes afro-brasileiras numa sociedade em que ser católico era a condição necessária para ser brasileiro. Introduz a seguir a questão do politeísmo, apresentado como característica importante das religiōes africanas, e discute o favorecimento do sincretismo que o politeísmo propicia. Trata, finalmente, desses dois aspectos, sincretismo e politeísmo, nas relações entre afro-brasileiros, católicos e evangélicos.
\end{abstract}

Palavras-chave: Sincretismo afro-brasileiro; Politeísmo afro-brasileiro; Intolerância religiosa; Monoteísmo versus politeísmo

Abstract: The present article presents the religious syncretism in the formation and posterior transformations of the Afro-Brazilians religions in a society where to be Catholic was a first condition to be Brazilian. Introduces the question of polytheism, presented as an important characteristic of the African religions and try to show as polytheism aids syncretism. Discusses, finally, what syncretism and polytheism can represent in the relationship between Afro-Brazilians, Catholics and Evangelicals.

Keywords: Afro-Brazilian syncretism; Afro-Brazilian polytheism; Religious intolerance; Monotheism against polytheism.

${ }^{1}$ Reginaldo Prandi é professor titular de sociologia da USP, aposentado, e pesquisador do CNPq. Entre seus livros mais recentes estão Mitologia do orixás, Segredos guardados, o romance policial Morte nos búzios e os infanto-juvenis Ifá, o Adivinho, Minha querida assombração, Jogo de escolhas, Feliz Aniversário, Contos e lendas afro-brasileiros e Contos e lendas da Amazônia, todos editados pela Companhia das Letras. Entre outros prêmios, recebeu o Prêmio Érico Vannucci Mendes 2001, outorgado pelo CNPq, SBPC e Ministério da Cultura, por sua contribuição à preservação da memória cultural brasileira. 
Um em cada cinco brasileiros costuma frequentar cultos ou serviços religiosos de alguma religiáo diferente da que professa. É uma estimativa aproximada para a cifra de $17 \%$ para brasileiros em geral encontrada pelo instituto DataFolha em pesquisa de alguns anos atrás. No mesmo levantamento, esse número subia a 19\% entre os católicos, crescia para $37 \%$ entre os umbandistas e chegava a $48 \%$ entre os seguidores do candomblé. Mais sectários, os evangélicos pentecostais mostravam-se numa cifra bem mais modesta: 9\% (Folha de S. Paulo, 6/5/2007).

$\mathrm{E}$ o que se vai fazer numa religião que não é a sua? Uns vão participar de atos com finalidade religiosa. Outros, presenciar ritos como casamento e funeral, numa atividade mais social que religiosa. Não raro, a coisa se faz por necessidade religiosa ou mágica, uma religião complementando outra. Uma só religião não basta. Isso é comum no Brasil, especialmente pelo caráter sincrético de nossas religiōes.

Umas mais, outras menos, toda religião é sincrética. Quando uma igreja pentecostal adota práticas mágicas afro-brasileiras, como é o caso do descarrego, mostrado pela televisão evangélica, ela toma por empréstimo de suas maiores rivais um rito mágico muito familiar ao brasileiro, seja ele umbandista, católico, evangélico etc. Igualmente, o catolicismo carismático foi buscar no pentecostalismo as práticas do falar em línguas estranhas e outros dons que, apesar da origem cristã comum, são especialmente estruturadoras do pentecostalismo (Prandi, 1998). O empréstimo aproxima as religiōes em termos de linguagem e reforça sua eficácia mágica. Se um fiel encontra na sua religião elementos presentes também em outras, a outra religião nunca lhe é inteiramente estranha. Afinal, costuma-se dizer que todos os caminhos levam a Deus.

Por razōes históricas de sua constituição, as religiōes afro-brasileiras são as que mais se aproximam de outras, primeira e especialmente do catolicismo, e em segundo plano de religiōes indígenas e do espiritismo kardecista. Pela densidade do sincretismo que se pode observar a olho nu, as religiōes afrobrasileiras, entre elas o candomblé, o xangô, o tambor de mina, o batuque e a umbanda, não raro, são classificadas numa categoria genérica denominada religiōes sincréticas. 
Quando o candomblé se formou, o catolicismo era a religião oficial do Brasil, e nenhuma outra era tolerada. Todo brasileiro, fosse branco, indígena ou africano, deveria ser batizado católico.

Antes de serem embarcados nos navios negreiros, ainda na África, os escravos eram batizados e introduzidos nas práticas rituais da Igreja católica. Quando não, a inclusão compulsória no catolicismo fazia-se no desembarque. Desse modo, os negros que instituíram no Brasil as religiōes afro-brasileiras eram, por força da sociedade da época, e da lei, também católicos. Acabaram por estabelecer paralelos entre as duas religiōes, identificando, por meio de símbolos ou patronagens comuns, orixás com santos católicos e Jesus Cristo.

No contexto cultural católico do Brasil do século XIX, o candomblé nascido desse encontro se firmou como religião subalterna e tributária do catolicismo, do qual ainda hoje tem dificuldade de se libertar para se constituir como religião autônoma. No lado de cá do Atlântico, mitos foram adaptados à nova realidade social, rituais ganharam feições condizentes com o novo território e os novos tempos, deuses africanos tornaram-se santos afro-brasileiros. A umbanda, surgida mais tarde do candomblé e do kardecismo, manteve e reforçou esse sincretismo. Não é estranho à umbanda e ao candomblé ter seus adeptos frequentando missas e sacramentos católicos. No fundo, também são católicos. A Igreja católica faz vistas grossas, assim como finge não ver seus fiéis buscando nos terreiros e centros ajuda no jogo de búzios, nos despachos e nos conselhos dos caboclos e pretos-velhos.

II

A religião africana no Brasil, ainda que resultante de uma reconstrução fragmentada, foi capaz de dotar o negro de uma identidade africana, de origem, que recuperava ritual e simbolicamente a família, o grupo étnico e a cidade perdidos para sempre na diáspora. Mas foi por meio do catolicismo que o negro pôde se encontrar e se mover no mundo real do dia a dia na sociedade do branco dominador, que era o responsável pela garantia de sua existência, ainda que em condições de privação e sofrimento, e que 
controlava sua vida quase completamente. Qualquer tentativa de superação da condição escrava, como realidade ou como herança histórica, implicava primeiro a necessária inclusão no mundo do branco. E logo passava a significar o imperativo de ser, sentir-se e parecer brasileiro. Os negros não podiam ser brasileiros sem ser ao mesmo tempo católicos. Podiam preservar suas crenças no estrito limite dos grupos formados por africanos e descendentes - muitas vezes reproduzindo simbolicamente a família e os laços familiares mediante a congregação religiosa, daí a origem dos terreiros de candomblé e das famílias de santo -, mas a inserção no espaço maior exigia uma identidade nacional, por assim dizer, uma identidade que refletisse o conjunto geral da sociedade católica.

O fim da escravidão, a formação da sociedade nacional estruturada em classes, o extravasamento das populações negras pelas amplitudes geográficas, com a criação de oportunidades sociais as mais diferentes, tudo isso só fez reforçar a importância do catolicismo para os negros. $\mathrm{O}$ próprio catolicismo, como cultura de inclusão, hegemônica, não fez oposições que não pudessem ser vencidas, ao fato de o negro manter, muitas vezes, uma dupla ligação religiosa ${ }^{2}$.

Assim, as religiões afro-brasileiras sempre foram devedoras e dependentes do catolicismo, ideológica e ritualmente. Só muito recentemente as religiões de origem negra começaram a se desligar do catolicismo, já numa época em que a sociedade brasileira não precisa mais do catolicismo como a grande e única fonte de transcendência que possa legitimá-la e fornecer-lhe os controles valorativos da vida social. Mas isso é um projeto de mudança nos referenciais de identidade que mal começou e que exige, antes, outras experiências de situar-se no mundo com mais liberdade e direitos de pertença.

A partir do Rio de Janeiro, lá pela década de 1930, a umbanda, que então nascia, retrabalhou muitos elementos religiosos de origem africana, que acabaram incorporados à cultura brasileira por um estamento negro que se diluía e se misturava aos brancos pobres na constituição das novas classes

2 Ainda hoje, frequentar mais de uma religião, ao menos circunstancialmente, é costume que se pode observar em parcela expressiva da população, sobretudo porque a religião pode ser vista também como serviço (Negrão, 2008). 
sociais numa cidade, então a capital federal, que era branca, mesmo quando proletária, era culturalmente europeia, valorizava a organização burocrática da qual vivia então boa parte da população residente e premiava o conhecimento pelo aprendizado escolar em detrimento da tradição oral, tão cara à tradição africana. Ao mesmo tempo, propiciava vigoroso processo de valorização de elementos nacionais, como o caboclo e o preto velho, que são espíritos de indígenas e escravos.

Tratava-se de limpar a religião nascente de seus elementos mais comprometidos com a tradição iniciática secreta e sacrificial, tomando por modelo o kardecismo, que expressava ideais e valores da nova sociedade capitalista e republicana, ali na sua capital. Os passos decisivos na formação da umbanda foram a adoção da língua vernácula, a simplificação da iniciação, a eliminação quase total do sacrifício de sangue. Manteve-se o rito cantado e dançado dos candomblés, bem como um panteão simplificado de orixás, já havia muitos anos sincretizados com santos católicos, reproduzindo-se um calendário litúrgico que segue o da Igreja católica. Entretanto, o centro do culto no seu dia a dia estará ocupado pelos guias, caboclos, pretos velhos e mesmo os exus masculinos e femininos, as pombagiras, já cultuados em antigos candomblés baianos e fluminenses, frutos de um sincretismo cujas fontes estão também fora do catolicismo (Camargo, 1961; Lewgoy, 2009; Prandi, 1996).

Assim, entre 1930 e o final dos anos 1950, mais ou menos, a história das religiōes afro-brasileiras está centrada no apagamento de características de origem africana e no sistemático ajustamento à cultura nacional de preponderância europeia, que é branca. $\mathrm{Na}$ contrapartida do processo de branqueamento, entretanto, muitas práticas e concepçôes religiosas de origem negra acabaram por contribuir decisivamente para a formação de uma identidade mestiça construída para o país no período, sobretudo no âmbito das artes, como foi no caso do samba (Prandi, 2005).

Mais adiante, a partir dos anos 1960, com a larga migração, saída do Nordeste em busca das grandes cidades industrializadas do Sudeste, o candomblé da Bahia começou a penetrar o bem estabelecido território da umbanda, e velhos umbandistas começaram a iniciar-se no candomblé, 
muitos deles abandonando os ritos da umbanda para se estabelecer como pais e mães de santo das modalidades mais tradicionais de culto aos orixás. Nesse movimento, a umbanda foi remetida de novo ao candomblé, sua velha e verdadeira raiz original, considerada pelos novos seguidores como sendo mais misteriosa, mais forte, mais poderosa que sua moderna e embranquecida descendente. Tratava-se de recuperar o que a umbanda desprezara, mas sem abandonar elementos da umbanda muito valorizados no mercado mágico e religioso. Foi o caso dos cultos quimbandistas dos exus e pombagiras agregados a amplo segmento no novo candomblé, num movimento sincrético que junta candomblé e umbanda, formando-se o que muitos chamam de umbandomblé. A umbanda dotou, por assim dizer, a religião tradicional afro-brasileira de todo um panteão, ritualística e visão de mundo da chamada esquerda da umbanda, ou quimbanda. Hoje é difícil encontrar um terreiro de orixá, vodum ou inquice sem os exus e pombagiras, em qualquer região do Brasil, seja qual for o nome que localmente se dê à religião afro-brasileira.

Os anos durante os quais o candomblé instalou-se em São Paulo, entre meados dos 1960 e os primeiros anos da década de 1970, marcam um período de vital efervescência no plano da cultura e das mentalidades. Profundas foram as mudanças em relação aos modos de vida e aos códigos intelectuais, quando a racionalidade foi posta sob suspeição, assim como a crença completa no conhecimento universitário e seus modelos fechados de explicação do mundo. Antevia-se o que viria mais tarde dar no chamado pós-moderno. O movimento de contestação dos anos 60 do século XX, que se iniciou na Europa e nos Estados Unidos, logo chegou ao Brasil, sobremaneira ao Sudeste, às grandes cidades, ganhando adeptos entre intelectuais e estudantes secundaristas e universitários.

São os anos da contracultura, da recuperação do exótico, do diferente, do original. Nesse período de intensa renovação cultural e agitação política - basta lembrar o golpe militar de 1964, os movimentos que o precederam e os longos anos de repressão ditatorial e de resistência por parte de estudantes, intelectuais, artistas e operários -, os movimentos da juventude de esquerda tiveram intensa atuação em áreas como teatro e música, ao mesmo tempo que 
se desenvolvia uma concepção de sociedade que implicava a valorização do pobre, do negro, do explorado e do marginalizado, em que se incluía a favela e o morro cariocas, que passaram a ser cantados pelos compositores e intérpretes da música popular de elite como polos de luta contra a injustiça social. A intelectualidade brasileira de maior legitimidade nos anos 60 participou ativamente de um projeto cultural de recuperação de origens, que remetia muito diretamente à Bahia e ao candomblé. Muitos elementos do sincretismo religioso afro-brasileiro foram incorporados à cultura brasileira não religiosa.

No plano religioso, começava o que chamei de processo de africanização do candomblé (Prandi, 1991), em que o retorno deliberado à tradição implicava o reaprendizado da língua, dos ritos e mitos que foram deturpados e perdidos na adversidade da diáspora; voltar à África não para ser africano nem para ser negro, mas para recuperar um patrimônio cuja presença no Brasil era agora motivo de orgulho, sabedoria e reconhecimento público. De certo modo, esse movimento de africanização, de volta às raízes, supunha a negação de elementos umbandistas recentemente incorporados ao novo candomblé. Mas não foi bem isso que se deu: expurgos e adoções, as duas coisas aconteciam ao mesmo tempo, numa época em que falar de contradições e dialética era mais do que moda. No final, o sentimento sincretista parece ter falado mais alto, e os novos candomblés africanizados acabaram encontrando um lugar onde manter com legitimidade os caboclos, exus e pombagiras que destoavam do que pudesse ser considerado genuinamente africano. Decorreu desse processo, em grande parte, uma umbanda atual que agrega elementos das mais diferentes religiōes e práticas mágicas, ao lado de um candomblé, sobretudo nas regiōes conquistadas mais recentemente, que cultiva elementos marcadamente umbandistas ou quimbandistas (Prandi, 2001; 2005).

Em suma, o culto aos orixás primeiro misturou-se ao culto dos santos católicos para ser brasileiro - forjou-se o sincretismo. Depois apagou elementos negros para ser universal e se inserir na sociedade geral - gestou-se a umbanda. Finalmente procurou seguir o caminho da africanização e dessincretização preocupado em estabelecer sua autonomia em relação ao catolicismo - o candomblé se transformou em religião para todos e em todas as partes do país. 
A religião tradicional que migrou e que se refez na cidade moderna foi assim se mostrando como espelho da sociedade da diferença e do pluralismo. Nessa sociedade secularizada, em que não há mais lugar para a religião única e hegemônica, capaz, como no passado recente, de ditar regras para a sociedade como um todo, nessa sociedade que não precisa mais de deuses, que seguem cultuados em vista agora das necessidades dos indivíduos, nessa sociedade o candomblé foi se expandindo como uma das inumeráveis religiōes da metrópole contemporânea.

A religião agora depende das forças de oferta e procura, devendo adaptar-se a novas situações e novas demandas. Reage às suas concorrentes, lançando mão da propaganda e dos meios eletrônicos de comunicação, simplificando sua linguagem em função de produtos religiosos cuja propalada eficácia é o atrativo dos neodevotos que a religião arrebata em massa. Sobretudo especializa-se, abrindo mão de sua velha natureza de cultura e instituição totalizadora, vocacionada para dar conta de todas as coisas. A religião se esparrama e se fragmenta, perde sua origem, que deve ser refeita a cada nova demanda, ganha espaços e mercado. É agora religião do mundo, onde tudo se sabe e onde tudo se consome, se vende e se compra. Para ser um dia, quem sabe, a religião do mercado sem fronteiras. Aí se pode observar a presença da religião dos orixás, aos quais se juntaram deuses africanos de outras procedências e entidades de origem brasileira, num jogo que refaz tradiçôes e oferece novas possibilidades de culto como nunca se viu, e como é próprio da sociedade secularizada e pluralista.

Nesse contexto, as religiōes afro-brasileiras não dependem mais do catolicismo como mecanismo de identidade para seus devotos. Não é mais preciso ser católico para ser brasileiro; pode-se ter qualquer religião, ou nenhuma. O sincretismo não faz mais sentido, e para muitos dos adeptos do candomblé, sobretudo sua liderança mais esclarecida, em todas as regióes do Brasil, retirar dessa religião afro-brasileira os elementos católicos faz parte desse retorno à origem, dessa volta à África, que é uma retomada de práticas e símbolos religiosos e não o desejo de retornar às condições de vida do negro, do escravo, do antigo. 
Ao negar o sincretismo, deixando para trás a religião da Igreja católica, seus ritos e santos, o novo candomblé tenta se pôr em pé de igualdade com o catolicismo, quer deixar de ser religião subalterna, já não se vê a si mesmo como a religião do escravo. Mas sempre vai esbarrar em oponentes poderosos, incomodados com sua presença no cenário religioso e dispostos a eliminá-lo.

III

No passado recente, o candomblé sofreu intensa perseguição por parte de autoridades do governo, da polícia e de muitos órgãos da imprensa, que mantiveram nas páginas de jornais campanhas odiosas contra uma prática religiosa que julgavam, preconceituosamente, magia negra, coisa do diabo, coisa de negro, enfim. Como se fosse uma praga prejudicial ao Brasil - e à sua civilização -, que devesse ser erradicada (Reis, 2008; Braga, 1995). $O$ preconceito racial, que considerava o negro africano um ser inferior ao homem branco, desdobrou-se em preconceito contra a religiáo fundada por negros escravos e livres. Ao longo de mais de um século, em diferentes partes do país, terreiros foram invadidos, depredados e fechados, pais e filhos de santo presos, objetos sagrados profanados, apreendidos e destruídos. Isso obrigou o candomblé a se esconder, buscando lugares distantes, às vezes no meio do mato, para poder realizar suas cerimônias em paz. Transformou-se numa religião de muitos segredos, pois tudo tinha que ocultar dos olhares impiedosos da sociedade branca e da sanha policial. O sincretismo católico, serviu-lhe também de guarida e disfarce. A presença de um altar com os santos católicos ocupando um lugar de relevo no barracão do candomblé indicava, e em muitos terreiros ainda indica, que as pessoas ali reunidas eram católicas, antes de mais nada.

Nada disso é novidade: quem estuda as religiōes afro-brasileiras sempre encontra a questão da intolerância. Quando a perseguição por parte do governo, da imprensa e da polícia arrefeceu, por força de lei e mudanças sociais, inimigos religiosos revelaram-se mais fortes e intransigentes. Surgiam os neopentecostais, e a intolerância evangélica, já atuante, cresceu muito. Os ataques sistemáticos de muitas igrejas pentecostais às religiōes afro-brasileiras 
ganharam tamanho vulto e visibilidade que muitos autores não se intimidaram de os chamar de guerra religiosa (Soares, 1990; Mariz, 1997; Oro, 1997; Rabelo, 2005). Como resultado, o Brasil de hoje, em termos relativos, é religiosamente menos afro-brasileiro do que foi há vinte ou trinta anos. Nesta que é hoje, além de predominantemente católica, a maior nação pentecostal do mundo, o espaço relativo das religiões afro-brasileiras vem diminuindo dramaticamente (Mariano, 2001; Prandi, 2005).

Derrotar as religiōes afro-brasileiras é item explícito do planejamento expansionista pentecostal. Certas igrejas, copiando práticas empresariais comuns em nossos dias, estabelecem metas, e entre as metas que um pastor deve alcançar está o fechamento de um dado número de terreiros existentes no lugar. Não basta converter membros dos terreiros: é preciso fechar seus templos, cortar o mal pela raiz. Entre um afro-brasileiro e outro, o alvo preferencial para a investida que visa à conversão são as lideranças, os pais e mães de santo; sabem que a família de santo não sobrevive sem a cabeça.

Umbanda e candomblé - e demais modalidades religiosas de origem africana - estão sempre na mira evangélica como religiões do diabo, que eles acreditam ser preciso combater a qualquer custo. As religiōes afrobrasileiras, de certo modo, oferecem munição aos evangélicos: por conta do sincretismo católico, entidades espirituais como os exus e pombagiras do panteão quimbandista são vistas e promovidas por muitos dos próprios seguidores do candomblé e da umbanda como formas do diabo. Ainda que se explique que no contexto doutrinário afro-brasileiro a dualidade cristã do bem contra o mal é superada pela visão africana que enxerga o bem e o mal como princípios constitutivos presentes em toda ação e seus agentes, o fato é que a iconografia dos exus e pombagiras usa à exaustão traços e símbolos característicos do diabo católico. A figura de exus de rabo, chifres e tridente funciona como emblema acirrante da causa evangélica. Pombagiras não ficam atrás na exibição de seus dotes eróticos. Difícil abandonar a imagem demoníaca que o sincretismo forjou para essas entidades e que agora se vira contra seus próprios criadores, como um tiro no pé. Na sua perseguição obstinada pelo diabo, o evangélico imagina que o tem bem à mão, ali no terreiro vizinho, incorporado na filha de santo, ao alcance de seu braço. 


\section{IV}

O candomblé desde sua origem foi capaz de criar mecanismos eficazes de sobrevivência em meio hostil, no caso a sociedade brasileira católica. Mudou, adaptou-se, sincretizou-se, se escondeu e se mostrou com dissimulação e disfarces eficientes. Sobreviveu procurando não competir com a religião dominante, mas se mostrando como uma espécie de conjunto ritual e doutrinário complementar justificado culturalmente pela memória africana do Brasil. Sempre foi visto mais como cultura do que como religião propriamente. Talvez como magia, sobretudo como folclore. $\mathrm{O}$ fato é que o candomblé aceitou plenamente o catolicismo.

Teria sido uma estratégia de sobrevivência? É crença generalizada que sim. Como a crença de que o sincretismo nasceu como disfarce, como uma mentira usada pelos escravos para enganar seus senhores, cantando e dançando para o santo católico quando, na verdade, estariam cantando e dançando para o orixá. Defendo a ideia de que a origem do sincretismo afro-católico está assentada em sentimentos sinceros, de que o sincretismo se instituiu não como artimanha, mas como resultado de relações de tolerância e assimilação decorrentes da condição politeísta da religião africana, que em solo brasileiro se encontrou com o politeísmo residual, difuso, mas efetivo do catolicismo ibérico e de seu culto aos santos ${ }^{3}$.

Essa relação não poderia se reproduzir igualmente no encontro das religiôes afro-brasileiras com as religiôes evangélicas, originadas de um protestantismo estritamente monoteísta. A análise do embate entre afro-brasileiros, católicos e evangélicos se repõe assim sob um outro ângulo, o das relações entre politeísmo e monoteísmo.

Faz parte da doutrina afro-brasileira acreditar que o mundo é governado pelos orixás, cada um cuidando de uma parte, numa espécie de divisão do trabalho divino. Além da regência que cada orixá desempenha sobre um aspecto da natureza, a cada um é reservada uma atividade específica no cuidado da sociedade, da cultura ou da psicologia do ser humano. Essa ideia de que o mundo é governado por diferentes deuses com poderes específicos

\footnotetext{
3 Para outras interpretações e aspectos do sincretismo católico nas religiōes afro-brasileiras,
} ver Valente, 1977; S. Ferretti, 1995; Sanchis, 1995. 
é politeísmo (Chevitarese; Cornelli, 2007; Segato, 2005). Também há uma divisão do trabalho sagrado entre os santos católicos - resquício do velho paganismo politeísta em que medrou o catolicismo primitivo em países da Europa. Esse poder de cada um sobre determinadas dimensões do mundo natural e social juntou santo e orixá numa só devoção. Também são unidos num só por seus feitos mitológicos notáveis e por símbolos de sua iconografia.

Aqui se desenha talvez a principal diferença entre as religióes afro-brasileiras e as evangélicas: o politeísmo dos afro-brasileiros, que junta diferentes crenças e adota santos e deuses de outras origens através de mecanismos como o sincretismo, versus o monoteísmo radical evangélico, tributário do protestantismo da Reforma, sectário, intolerante e combativo, que rejeita completamente a crença do outro, demoniza divindades, santos e entidades espirituais de outras origens e se propõe como missão religiosa a destruição do que lhe é religiosamente estranho.

É da natureza do candomblé aceitar o outro, assimilar a diferença. Já era assim na África, e é assim no Brasil. É próprio das religiōes politeístas.

No politeísmo clássico, como acontecia no Egito, na Grécia, no império Romano, a religião é um agregado de cultos de deuses diversos, nem sempre provenientes de uma mesma origem. As divindades convivem em relativa harmonia, cada uma com seus poderes, seus territórios e patronatos. Dispõem de templos próprios e sacerdotes particulares. $\mathrm{O}$ culto não é o mesmo para todos, nem os sacrifícios que lhes são devidos, nem os tabus, nem os demais preceitos e obrigaçôes. Os deuses e deusas, como os mortais, competem entre si e tentam alargar os limites de seu poder divino. Ainda assim, deuses estrangeiros são facilmente assimilados e adotados em terras estranhas. Deuses locais podem se transformar em divindades nacionais, migram com seus devotos, têm seu culto ampliado com a vitória de seu povo sobre outros povos, declinam junto com sua gente.

Porque cada deus desempenha um papel diferente na divisão do trabalho divino, as diferentes religiōes politeístas em contato umas com as outras acabam estabelecendo paralelo entre seus deuses, às vezes os igualando como manifestações de uma mesma divindade. A maioria dos deuses romanos, muitos deles herdados dos etruscos, podia ser cultuada como manifestações 
dos equivalente deuses gregos olímpicos. Nesse jogo de equivalências, também podemos situar os orixás.

No Brasil, os negros estabeleceram conhecida correspondência dos orixás com os santos católicos: Xangô com São Jerônimo, pelo domínio do trovão; Oxóssi com São Jorge, pela luta mitológica contra o dragão da maldade; Ogum com Santo Antônio, pela capacidade guerreira de cada um; Nanã com Santana, pela senioridade; Logum Edé com São Miguel Arcanjo, por causa da balança que os simboliza; Iroco com São Francisco, pelo convívio com a natureza; Iemanjá com Nossa Senhora, pela maternidade; Iansã com Santa Bárbara, pelo poder contra o raio; Exu com o Diabo por atributos eróticos e comportamento transgressivo; Oxalá com Jesus Cristo, pela posição superior de cada um nas duas religióes etc.

Da Oxum, deusa do amor do candomblé, pode-se apontar grande aproximação com a Vênus romana, a Afrodite grega e a Hátor egípcia, assim como Xangô, senhor da justiça, remete a Júpiter, Zeus e Amon, enquanto Omulu lembra Esculápio e Amon. Para cada deus daqui haverá um deus de lá, e em muitos casos divindades de culturas diferentes são representadas pelo mesmo símbolo, como o espelho de Vênus e Oxum, o machado duplo de Zeus e Xangô, o arco e flecha de Artêmis e Oxóssi.

Exemplo emblemático da difusão de um culto e incorporação de sua divindade a panteōes de outras religiōes é o caso da deusa egípcia Ísis, que junto com seu irmão e marido Osíris ocupou o lugar de maior relevo no panteão egípcio. Dali foi levada para a Grécia e da Grécia para Roma. Foi cultuada em quase todo o território do império romano. Desapareceu com a queda de Roma e a ascensão do catolicismo, para ressurgir, quase dois mil anos depois, como divindade de desaparecidas e agora restauradas religiōes da Inglaterra antiga, ocupando recentemente lugar de honra na recém-criada wicca, a religião da deusa, que prolifera no Brasil. Pois há quem creia tratarse do orixá Iansã, do vodum Sobô, do inquice Matamba. E por que não de Santa Bárbara? Se não a mesma divindade, um de seus avatares, uma outra manifestação da mesma deusa.

No Brasil, na formação das chamadas naçōes de candomblé (Lima, 1984), divindades de diferentes etnias africanas também sincretizaram-se 
entre si. A correspondência entre orixás, voduns e inquices - divindades iorubás, fons e bantas - é quase completa, o nome de um se referindo ao de outro e incluindo o de santos católicos. Xangô, assim, também é Zázi, Luango, Badé, São Jerônimo, São João e São Pedro. Oxóssi ou Odé é Gongobira, Mutacalombo, Azacá, Aguê, São Sebastião e São Jorge. Ogum é Roximucumbe, Doçu, Santo Antônio e São Jorge. Exu é Aluviá, Bombogira, Elegbara, o Diabo e também São Gabriel Arcanjo. Iansã ou Oiá é Sobô, Matamba, Bamburucema e Santa Bárbara. Iemanjá é Caiá, Abê e Nossa Senhora, enquanto Oxalá pode ser referido como Lembá, Lissá e Jesus Cristo. E assim por diante, podendo o Deus cristão ser invocado como Zâmbi, Avievodum, Olorum e Olodumare.

A característica politeísta da religião dos orixás contribuiu enormemente para a formação do candomblé como religião sincrética. Adotar santos, que identifica com suas divindades ou seus avatares, incorporar rituais e aceitar valores católicos se deu de modo tão normal como a anterior incorporação, ainda na África, de muitos voduns, divindades fons, ao panteão dos orixás iorubanos. $\mathrm{Na}$ concepção politeísta, o deus estrangeiro fortalece a religião; não é visto como um concorrente, mas como um poder a mais com que se pode contar. No fundo, a outra religião não é muito diferente. Vem das origens pagãs o politeísmo católico, sobretudo quando se pensa na religião do povo, não na religião dos teólogos, órgãos oficiais e cânones que afirmam, atestam e impõem a religião como monoteísta, de um deus supremo e único. Também na religião dos orixás há um deus supremo, Olorum ou Olodumare, mas quem exerce de fato o poder divino sobre o mundo são os orixás, os outros deuses (Verger, 1996). E os santos fazem o quê? Também não se especializaram em resolver causas específicas?

Um politeísmo explícito, o africano, encontrou-se no Brasil com um politeísmo residual, formalmente inexistente, mas bem preservado no imaginário católico. Foi bom para ambas as religiōes. Serviu para acomodar na Igreja católica os membros dos terreiros de candomblé, e para dar aos seguidores dos orixás a identidade católica necessária à sobrevivência na sociedade de então, quando a condição primeira de ser brasileiro era ser católico, não custa repetir. 
É outra a base doutrinária dos evangélicos: um efeito decisivo da Reforma protestante sobre a natureza do cristianismo foi acabar de vez com o politeísmo disfarçado que vicejou no catolicismo. Até a Virgem Maria, tão cara aos católicos, foi banida das celebraçōes protestantes. Essa marca monoteísta explícita foi sempre enfatizada também pelos evangélicos que vieram depois. Além de monoteísta, o evangelicalismo, nascido como oposição doutrinária ao catolicismo, constituiu-se como uma espécie de religião de revisão permanente de verdades teológicas. E desde sempre se comporta como seita, no mais estrito sentido sociológico da palavra em termos weberianos. Seitas julgam-se portadoras da única verdade.

Enquanto as religiôes afro-brasileiras aceitam as outras religiôes, assimilam seus valores e práticas, adiciona empréstimos a seu panteão, ampliando cada vez mais os limites do sincretismo - hoje muito além do catolicismo, como mostra a umbanda Nova Era -, o pentecostalismo radicaliza sua definição monoteísta e orienta seu trabalho de conversão com o sentido de promover uma espécie de limpeza espiritual do mundo, combatendo o que para ele são os falsos deuses - já inadmissíveis por sua pluralidade numérica. Reforça com determinação seu caráter sectário, de que se abastece em guerra aberta contra seus inimigos preferenciais, os afro-brasileiros. À orientação de que todo o mal resulta da ação do diabo, que deve ser combatido a cada instante, em todo lugar, por todo cristão, soma-se à concepção de que o demônio se personifica nos orixás, nas entidades e nos guias espirituais cultuados pela umbanda e pelo candomblé.

E como reagem os afro-brasileiros? Não reagem. A guerra de que são vítimas para eles não faz sentido. Têm até dificuldade em admitir sua existência.

As religiōes afro-brasileiras não fazem proselitismo nem são capazes de enxergar as outras religiōes como oponentes, não veem nelas ameaça à sua própria sobrevivência. Em matéria de convivência com outras religiôes, as afro-brasileiras são especialmente tolerantes. O candomblé, o xangô, o tambor de mina, o batuque e a umbanda são religióes de pequenos grupos, os terreiros afro-brasileiros, cada um deles organizado em torno de um pai ou mãe de santo. Tendo como modelo o culto doméstico, os terreiros 
se constituíram como autônomos e autossuficientes, não contando com nenhuma organização institucional eficaz que os unifique ou que permita uma ordenação mínima capaz de estabelecer planos e estratégias comuns na relação da religiāo afro-brasileira com as outras religiōes e o resto da sociedade. Não há autoridade acima do pai ou da mãe de santo, cada um em seu terreiro. Há grande competição entre os terreiros, e os laços de solidariedade entre eles são frágeis e circunstanciais, meramente protocolares. Cada chefe preocupa-se com a sobrevivência de seu próprio grupo de culto, sem que os diferentes grupos se organizem e se juntem para reagir às ameaças à religião como um todo. As iniciativas já experimentadas para se defenderem conjuntamente do ataque de outras religiōes são tímidas e incipientes.

Por tudo isso, a convivência estabelecida no passado entre as religiōes dos orixás e o catolicismo dos santos não se repetiu quando as religióes afro-brasileiras se encontraram com as igrejas evangélicas. Nem poderia. No enfrentamento com os aguerridos evangélicos, o recurso do sincretismo lhes é de nenhuma valia.

\section{REFERÊNCIAS}

BRAGA, Júlio Santana. Na gamela do feitiço: repressão e resistência nos candomblés da Bahia. Salvador: Edufba, 1995.

CAMARGO, Candido Procopio Ferreira de. Kardecismo e umbanda. São Paulo: Pioneira, 1961.

CHEVITARESE, A. L.; CORNELLI, G. Judaismo, cristianismo, helenismo: ensaio sobre interações culturais no Mediterrâneo Antigo. São Paulo: Annablume, 2007.

FERRETTI, Sérgio Figueiredo. Repensando o sincretismo: estudo sobre a Casa das Minas. São Paulo: Edusp, 1995.

LEWGOY, Bernardo (Org.). Espiritismos. Porto Alegre, Debates do NER n. 15, 2009. 
LIMA, Vivaldo da Costa (Org.). Encontro de naçôes de candomblé. Salvador: Inamá, 1984.

MARIANO, Ricardo. Análise sociológica do crescimento pentecostal no Brasil. Tese de doutorado em Sociologia. São Paulo: Universidade de São Paulo, 2001.

MARIZ, Cecília Loreto. Reflexões sobre a reação afro-brasileira à guerra santa. Guerra Santa. Porto Alegre, Debates do NER, n. 1, p. 96-103, 1997.

NEGRÃO, Lísias Nogueira. Pluralismo e multiplicidades religiosas no Brasil. Sociedade e Estado. Brasília, v. 23, n. 2, p. 261-279, 2008.

ORO, Ari Pedro. Neopentecostais e brasileiros, quem vencerá esta guerra? Debates NER, Porto Alegre, v. 1, n. 1, p. 10-37, 1997.

PRANDI, Reginaldo. Os candomblés de São Paulo: a velha magia na metrópole nova. São Paulo: Hucitec \& Edusp, 1991.

. Herdeiras do axé: sociologia da religiões afro-brasileiras. São Paulo: Hucitec, 1996.

(Org.). Encantaria brasileira: o livro dos mestres, caboclos e encantados. Rio de Janeiro: Pallas, 2001.

. Segredos guardados: orixás na alma brasileira. São Paulo: Companhia das Letras, 2005.

RABELO, Miriam Cristina Marcilio. Rodando com o santo e queimando com o espírito: possessão e a dinâmica de lugar no candomblé e pentecostalismo. Ciencias sociales y religión. Porto Alegre, v. 7, n. 7, p. 11-37, 2005. REIS, João José. Domingos Sodré, um sacerdote africano: escravidão, liberdade e candomblé na Bahia do século XIX. São Paulo, Companhia das Letras, 2008.

SANCHIS, Pierre. As tramas sincréticas da história. Revista Brasileira de Ciências Sociais. São Paulo, n. 28, p. 123-130, jun. 1995.

SEGATO, Rita. Santos e daimones: o politeísmo afro-brasileiro e a tradição arquetipal. 2 ed. Brasília: Editora da UnB, 2005. 
SOARES, Mariza de Carvalho. Guerra santa no país do sincretismo. In: Sinais dos tempos: diversidade religiosa no Brasil. Rio de Janeiro, Cadernos do Iser 23, p. 75-104, 1990.

VALENTE, Waldemar. Sincretismo religioso afro-brasileiro. 3 ed. São Paulo: Nacional, 1977.

VERGER, Pierre Fatumbi. The Yoruba High God. Ibadan: University of Ifé, 1966. 